\title{
EFICÁCIA DO TRATAMENTO COM OMALIZUMAB NA URTICÁRIA CRÓNICA ESPONTÂNEA RESISTENTE À TERAPÊUTICA HABITUAL COMBINADA
}

Pedro Morais Silva', Ana Mendes', Ana Célia Costa', Manuel Pereira Barbosa'

'Serviço de Imunoalergologia/Immuneallergology Department, Hospital de Santa Maria EPE, Centro Hospitalar Lisboa

Norte, Lisboa, Portugal

RESUMO - A urticária crónica (UC) consiste num quadro cutâneo de duração superior a 6 semanas, caracterizada pelo aparecimento de lesões máculo-papulares eritematosas e pruriginosas, com uma duração individual inferior a 24 horas. É uma patologia relativamente frequente que causa morbilidade significativa. Atualmente, o seu tratamento com fármacos para além dos anti-histamínicos-H1 não foi exaustivamente estudada.

Descrevemos um caso de UC grave, resistente à terapêutica convencional com doses elevadas de anti-histamínicos$-\mathrm{H} 1$, corticodependente, no qual o tratamento com o anticorpo monoclonal anti-lgE omalizumab permitiu o controlo da urticária e a interrupção de corticoides sistémicos. Não se observaram reações adversas e o fármaco permaneceu eficaz ao longo de 18 meses de terapia.

É posteriormente apresentada uma revisão da literatura relativa à utilização deste fármaco, com ênfase nas suas características a longo prazo.

PALAVRAS-CHAVE - Antialérgicos; Anticorpos monoclonais; Anti-histamínicos-H1; Terapia combinada; Urticária.

\section{SUCCESSFUL USE OF OMALIZUMAB IN A PATIENT WITH H1- ANTIHISTAMINE-REFRACTORY CHRONIC SPONTANEOUS URTICARIA}

ABSTRACT - Chronic urticaria (CU) is characterized by an evanescent, itchy wheal and flare reaction that does not resolve completely after 6 weeks. It is a relatively frequent disease that causes significant morbidity. Its therapy with drugs other than $\mathrm{H} 1$-antihistamines has not yet been exhaustively studied, but recently some promising treatment options have been described.

We describe a case of severe, corticosteroid-dependent CU that was resistant to conventional treatment with high doses of $\mathrm{H} 1$-antihistamines. In this case, treatment with omalizumab, an anti-IgE monoclonal antibody, allowed control of urticaria symptoms and permitted corticosteroid interruption. No adverse reactions were reported and the drug remained effective during 18 months of therapy.

We present a review of the available literature concerning the use of omalizumab in $C U$, emphasizing information about its long-term efficacy.

KEY-WORDS - Anti-allergic agents; Antibodies, monoclonal; Histamine H1 antagonists; Drug therapy, combination; Urticaria.

Conflitos de interesse: Os autores declaram não possuir conflitos de interesse.

No conflicts of interest.

Suporte financeiro: O presente trabalho não foi suportado por nenhum subsídio ou bolsa.

No sponsorship or scholarship granted. 


\title{
Caso Clínico
}

\begin{abstract}
Direito à privacidade e consentimento escrito / Privacy policy and informed consent: Os autores declaram que pediram consentimento ao doente para usar as imagens no artigo. The authors declare that the patient gave written informed consent for the use of its photos in this article.
\end{abstract}

Recebido/Received - Outubro/October 2013; Aceite/Accepted - Dezembro/December 2013

Dr. Pedro Morais Silva

Tv. Henrique Cardoso 96, RC

1700-288 Lisboa, Portugal

Email: pedrotiagosilva@gmail.com

Tel.: +351917374928

\section{INTRODUÇÃO}

A urticária é caracterizada pelo aparecimento de lesões máculo-papulares eritematosas, pruriginosas, com uma duração individual inferior a 24 horas, associadas ou não a angioedema. Quando esta sintomatologia persiste mais de 6 semanas denomina-se de urticária crónica (UC). Esta patologia pode ser induzida quer por estímulos físicos (urticária física), quer por outros estímulos (colinérgica, aquagénica, etc) ou ocorrer na ausência de um desencadeante específico classificando-se então como urticária crónica espontânea (UCE)'.

Apesar da etiologia ser desconhecida, em aproximadamente $50 \%$ dos casos de UCE ${ }^{1}$ foram identificados autoanticorpos anti-lgE e/ou anti-FceRl, o que parece sugerir a existência dum mecanismo autoimune subjacente.

A UC é uma patologia relativamente frequente ${ }^{2}$, com impacto significativo na qualidade de vida, afetando sono, atividades diárias, vida profissional e interação social.

De acordo com as últimas recomendações da European Academy of Allergy and Clinical Immunology (EAACI)/Global Allergy and Asthma European Network (GA2LEN)/European Dermatology Forum (EDF)/World Allergy Organization (WAO) ${ }^{3}$, o objetivo do tratamento de todos os tipos de urticária deve ser o controlo total dos seus sintomas. Para tal, as causas subjacentes devem ser investigadas e se possível eliminadas e tratamento sintomático deve ser instituído de acordo com a sua gravidade. Os fármacos de primeira linha são os anti-histamínicos- $\mathrm{H} 1$ não-sedativos, que nos casos recalcitrantes podem ser administrados em doses até 4 vezes superiores à habitualmente utilizada. Na ausência de resposta satisfatória, o anti-histamínico deve ser alterado ou adicionado um antagonista do recetor dos leucotrienos. A última linha terapêutica, inclui diversos fármacos, como os antihistaminicos- $\mathrm{H} 2$, a ciclosporina, a dapsona e o omalizumab. Exacerbações de UCE podem ser tratadas com corticóides sistémicos, devendo ser evitados tratamentos prolongados devido aos seus efeitos secundários inerentes ${ }^{3}$.

De modo a uniformizar os critérios de avaliação destes doentes na prática clínica, nomeadamente a gravidade da urticária, as recomendações sugerem a utilização do urticaria activity score (UAS), no qual são somados pontos atribuídos à intensidade do prurido (0-nenhum a 3 -intenso) e número de pápulas ( 0 -nenhumas a 3 -mais de 12), num total de 0 a 6 valores diários'.

O omalizumab (Novartis, Suíça) é um anticorpo monoclonal $\lg G$ humanizado, que através da ligação ao domínio Ce3 da lgE livre, impede a ligação desta aos recetores de alta e baixa afinidade (Fc\&RI e Fc\&RII), presentes nas membranas dos mastócitos, basófilos, eosinófilos e linfócitos, reduzindo assim a libertação de mediadores inflamatórios como histamina, leucotrienos e citocinas ${ }^{4}$. Reduz também a expressão de recetores FceRI na superfície dos basófilos e previne o aumento dos seus níveis induzidos pela lgE nos mastócitos cutâneos $^{5}$. Este fármaco encontra-se aprovado no nosso país para o tratamento de asma alérgica persistente moderada a grave. A sua administração é subcutânea, em intervalos de duas a quatro semanas, sendo a dose na asma individualizada em função do valor da lgE total sérica e do peso do doente. Apresenta um bom perfil de tolerância, estando descritos efeitos adversos pouco frequentes, na sua maioria ligeiros, embora já tenham sido reportados raros casos de anafilaxia ${ }^{6}$.

Desde 2007, vários casos de UCE tratados com omalizumab com sucesso com têm sido descritos na 
literatura ${ }^{7,8}$. Dois estudos multicêntricos, controlados, randomizados e duplamente cegos avaliaram a eficácia deste tratamento num grupo de 90 doentes com $\mathrm{UCE}^{9}$ e num subgrupo de 49 doentes com UCE e anticorpos anti-tiroperoxidase ${ }^{10}$. Ambos demonstraram um efeito rápido e eficaz de omalizumab nos sinais e sintomas da UCE. Subsequentemente, dois estudos ${ }^{11,12}$ desenhados para avaliar a segurança e eficácia do fármaco no tratamento de UCE em doentes dos 12 aos 75 anos, demonstraram que o fármaco tem um bom perfil de segurança e que é eficaz, em doses fixas de $300 \mathrm{mg}$ a cada 4 semanas, a controlar os sintomas de UCE, em alguns casos imediatamente após a primeira dose.

O omalizumab está disponível na Europa desde 2005 e no nosso hospital desde 2007. O objetivo deste trabalho é reportar a eficácia e segurança do omalizumab no tratamento da UCE grave corticodependente, resistente a outras terapêuticas de última linha, através da descrição de um dos doentes tratados no nosso Hospital de Dia de Imunoalergologia.

\section{CASO CLÍNICO}

Descreve-se o caso de uma doente caucasiana de 23 anos, natural de Lisboa, referenciada à consulta de Imunoalergologia por queixas com duração de 8 semanas de máculas e pápulas eritematosas e pruriginosas, generalizadas de duração individual inferior a 24 horas, com desaparecimento à digito-pressão e edema ocasional das mãos e pés, sem fatores desencadeantes aparentes. Os testes cutâneos por picada e análises laboratoriais (incluindo função tiroideia, valores de complemento e imunoglobulinas) não apresentavam alterações. Não foram identificados anticorpos anti-tiroideus ou outros autoanticorpos e as serologias virais foram negativas. O teste de soro autólogo, realizado para determinação de autoreactividade, foi positivo. $\mathrm{Na}$ avaliação inicial, a doente apresentava queixas de prurido intenso e pápulas em cerca de 10 localizações simultaneamente (UAS=5).

O controlo da patologia foi insatisfatório com a utilização alternada de diversos anti-histamínicos-H1 em doses elevadas (ebastina, levocetirizina $4 \mathrm{x} / \mathrm{dia}$ ) em associação com ranitidina $300 \mathrm{mg} /$ dia e montelucaste $10 \mathrm{mg} / \mathrm{dia}$, pelo que foi iniciada prednisolona numa dose inicial de $40 \mathrm{mg} /$ dia. Esta foi eficaz na redução de sintomas, mas as diversas tentativas de redução da dose abaixo de $30 \mathrm{mg} /$ dia resultaram invariavelmente no reaparecimento das lesões cutâneas. Nesta fase, a doente foi proposta para tratamento mensal com imunoglobulina $\mathrm{G}$ humana endovenosa $400 \mathrm{mg} / \mathrm{kg} /$ dia. Apresentou, após 2 meses de terapêutica uma resposta parcialmente favorável (UAS $=2)$, que possibilitou uma redução de corticoide para $10 \mathrm{mg} /$ dia, não sendo possível reduzir para além desta dose por reaparecimento das lesões. Esta foi portanto mantida durante 30 meses, após os quais a doente apresentava facies cushingóide, aumento de peso de $35 \mathrm{~kg}$ (correspondente a $58 \%$ do seu peso original, IMC $\left.33,5 \mathrm{~kg} / \mathrm{m}^{2}\right)$ e aumento do perímetro abdominal (86 para $102 \mathrm{~cm}$ ). Foi então interrompida a imunoglobulina e feita proposta para terapêutica com omalizumab subcutâneo $300 \mathrm{mg}$ de $4 / 4$ semanas. A doente assinou consentimento informado antes do início do tratamento.

Após a primeira administração observou-se melhoria evidente da urticária, com desaparecimento do prurido e redução do número de pápulas $(U A S=1)$. Antes da terceira administração, a doente encontrava-se sem lesões e sem prurido (UAS=0), pelo que se reduziu gradualmente a prednisolona e ebastina e se interrompeu ranitidina e montelucaste.

Não foram observados efeitos adversos associados à administração do fármaco. Todas as administrações foram efetuadas sob vigilância, em hospital de dia de Imunoalergologia. Após suspensão da prednisolona observou-se gradualmente reversão da facies cushingóide, diminuição de peso e do perímetro abdominal.

Após 12 meses de tratamento com omalizumab, devido à boa evolução do quadro, os intervalos entre cada dose de omalizumab foram progressivamente aumentados (para $6 / 6$ e posteriormente $8 / 8$ semanas). Aos 18 meses de tratamento, após um intervalo de 8 semanas entre doses, a doente encontrava-se assintomática, pelo que se optou pela suspensão de omalizumab. Doze semanas depois, verificou-se reaparecimento das lesões cutâneas e prurido intenso, com ausência de resposta à terapêutica convencional semelhante à anterior. A terapêutica com omalizumab foi reintroduzida, mais uma vez com resultados favoráveis após primeira administração.

\section{DISCUSSÃO}

A UCE é uma doença que causa morbilidade significativa. Atualmente, o tratamento desta patologia com fármacos para além dos anti-histamínicos não foi exaustivamente estudada e frequentemente depende da experiência individual de cada centro. Apresentamos um caso de UCE grave resistente à terapêutica convencional em doses elevadas, corticodependente, 


\section{Caso Clínico}

no qual o tratamento com omalizumab permitiu o controlo da urticária e remissão dos efeitos secundários da corticoterapia sistémica prolongada.

O omalizumab tem como indicação o tratamento de asma alérgica grave, mas tal como em vários estudos europeus e americanos ${ }^{11,12}$, no nosso Serviço tem sido demonstrada a sua utilização com sucesso no tratamento de $\mathrm{UCE}^{13,14}$ e eczema atópico ${ }^{15,16}$.

O omalizumab demonstrou ser um fármaco seguro. Todas as sessões foram efetuadas de acordo com um protocolo de observação pós-administração e não se observaram efeitos adversos, imediatos ou tardios.

Parece ocorrer uma melhoria rápida das manifestações cutâneas, sendo frequente a resolução total de sintomas antes da quarta administração e em alguns casos tão cedo como 48 horas após a primeira injecção $0^{9,11-14}$. No nosso caso, a doente apresentou controlo total da patologia após a segunda administração do fármaco. O mecanismo subjacente à rapidez desta resposta é ainda desconhecido, mas sugere a existência de um mecanismo de acção distinto do que ocorre em doentes asmáticos. Estudos que avaliaram a cinética do recetor $\mathrm{Fc \varepsilon RI}^{4}$ após a administração sugerem que antes da diminuição do número de recetores, uma redução rápida dos níveis da IgE plasmática poderá, de forma inespecífica, inibir a desgranulação dos mastócitos e basófilos por mecanismos independentes da densidade de recetores à superfície ${ }^{5}$. Mais estudos seriam necessários para comprovar inequivocamente esta teoria.

A positividade do teste do soro autólogo nesta doente parece apontar para a existência de um fator de autoreatividade em circulação. Não foi realizada a pesquisa de autoanticorpos anti-lgE e/ou anti-FceRI pelo indisponibilidade do método no nosso centro, pelo que não pode ser estabelecido o diagnóstico definitivo de UC autoimune, de acordo com os consensos mais recentes ${ }^{17}$. No entanto, o omalizumab parece ser eficaz em doentes com UC independentemente da presença de auto-imunidade 8 .

O mecanismo através do qual omalizumab induz remissão a longo-prazo é também pouco claro. Os estudos que incluíram um período de seguimento verificaram que a maioria dos doentes com $U C$ regressa ao seu estado clínico prévio, após aproximadamente 10 semanas da interrupção do fármaco. No caso apresentado, os sintomas surgiram ligeiramente mais tarde, na $12^{a}$ semana após suspensão. Assim, o omalizumab não aparenta ser, na maioria dos casos, uma terapêutica curativa - Embora seja eficaz no controlo sintomático, não altera a história natural da doença. Porém, como a UC é habitualmente uma patologia autolimitada, a utilização judiciosa deste fármaco poderá providenciar alívio a doentes graves, com impacto significativo na sua qualidade de vida, durante o período de maior atividade da doença, quando as linhas terapêuticas anteriores falham.

Não existem recomendações acerca da melhor forma de manejar o fármaco a longo-prazo. Da experiência dos autores, após estabilização da doença, já que alguns doentes parecem permanecer assintomáticos para além do período de 4 semanas, parece lícito tentar aumentar gradualmente o intervalo entre administrações, salvaguardando-se que do ponto vista teórico, existe pouca probabilidade que após 8 semanas exista ação farmacológica de omalizumab.

Em resumo, o tratamento com omalizumab parece ser uma alternativa segura e eficaz em doentes com UC grave e resistente a outros tratamentos. Apresenta um início de ação rápida e não parece perder a sua eficácia pelo menos após 18 meses. No entanto, pode ter efeitos secundários e carece de estudos que estabeleçam a forma mais eficaz para a sua utilização a longo-prazo. A sua administração deve ser bem fundamentada e efetuada em centros experientes com a sua utilização.

\section{BIBLIOGRAFIA}

1. Zuberbier T, Asero R, Bindslev-Jensen C, Canonica GW, Church MK, Giménez-Arnau A, et al. EAACl/ GA(2)LEN/EDF/WAO guideline: definition, classification and diagnosis of urticaria. Allergy. 2009; 64(10):1417-26.

2. Zazzali JL, Broder MS, Chang E, Chiu MW, Hogan DJ. Cost, utilization, and patterns of medication use associated with chronic idiopathic urticaria.Ann Allergy Asthma Immunol. 2012; 108(2):98-102.

3. Zuberbier T, Asero R, Bindslev-Jensen C, Canonica GW, Church MK, Giménez-Arnau A, et al. EAACl/ GA(2)LEN/EDF/WAO guideline: management of urticaria. Allergy. 2009; 64(10):1427-43.

4. Beck LA, Marcotte GV, MacGlashan D, Togias A, Saini S. Omalizumab-induced reductions in mast cell Fcepsilon RI expression and function. J Allergy Clin Immunol. 2004; 1 14:527-30.

5. Oliver JM, Tarleton CA, Gilmartin L, Archibeque T, Qualls CR, Diehl L, et al. Reduced FcepsilonRl-mediated release of asthma-promoting cytokines and chemokines from human basophils during omalizumab therapy. Int Arch Allergy Immunol. 2010; 151:275-84. 


\section{Caso Clínico}

6. Corren J, Casale TB, Lanier B, Buhl R, Holgate S, Jimenez P. Safety and tolerability of omalizumab. Clin Exp Allergy. 2009; 39(6):788-97.

7. Spector SL, Tan RA. Effect of omalizumab on patients with chronic urticaria. Ann Allergy Asthma Immunol. 2007; 99(2):190-3.

8. Ferrer M, Gamboa P, Sanz ML, Goikoetxea MJ, Cabrera-Freitag $P$, Javaloyes $G$ et al. Omalizumab is effective in nonautoimmune urticaria. J Allergy Clin Immunol. 2011; 127(5):1300-2.

9. Saini S, Rosen KE, Hsieh HJ, Wong DA, Conner E, Kaplan A et al. A randomized, placebo-controlled, dose-ranging study of single-dose omalizumab in patients with $\mathrm{Hl}$-antihistamine-refractory chronic idiopathic urticaria. J Allergy Clin Immunol. 2011; 128(3):567-73.

10. Maurer M, Altrichter S, Bieber T, Biedermann T, Bräutigam $M$, Seyfried $S$ et al. Efficacy and safety of omalizumab in patients with chronic urticaria who exhibit IgE against thyroperoxidase. J Allergy Clin Immunol. 2011 ; 128(1):202-9.

11. Maurer M, Rosen K, Hsieh HJ, Saini S, Grattan C, Gimenez-Arnau A, et al. Omalizumab for the treatment of chronic idiopathic or spontaneous urticaria. N Engl J Med. 2013; 368:924-35.

12. Kaplan A, Ledford D, Ashby M, Canvin J, Zazalli
J,Conner $\mathrm{E}$, et al. Omalizumab in patients with symptomatic chronic idiopathic/spontaneous urticarial despite standard combination therapy. J Allergy Clin Immunol. 2013; 132:101-9.

13. Costa AC, Silva PM, Dias JG, Mendes A, Pedro E, Barbosa MP. Treating Chronic Urticaria With Omalizumab - Our Experience In An Immunoallergology Department. J Allergy Clin Immunol. 2012; 129(2):AB225.

14. Costa AC, Silva PM, Dias JG, Mendes A, Pedro E, Barbosa MP. Efficacy of omalizumab in seven patients with treatment-resistant chronic spontaneous urticaria. Allergy. 2012; 67(96):452.

15. Luz S, Silva PM, Costa AC, Santos AS, Pedro E, Barbosa MP. O Papel do Omalizumab na Dermatite Atópica Grave. Rev Port Dermatol Venereol. 2011, 69 (2): 34-9.

16. Mendes AM, Costa AC, Luz S, Pedro E, Barbosa MP. Omalizumab - one year experience in the treatment of severe Atopic dermatitis. J Allergy Clin Immunol. 2012; 129(2):AB38.

17. Konstantinou GN, Asero R, Ferrer M, Knol EF, Mau$\operatorname{rer} M$, Raap $U$ et al. EAACl taskforce position paper: evidence for autoimmune urticaria and proposal for defining diagnostic criteria. Allergy. 2013; 68(1):2736. 